\title{
Retraction Note: Research on green plant development and forest asset accounting based on GIS system data
}

\author{
Shuting Deng ${ }^{1} \cdot \mathrm{Yi} \mathrm{Xia}^{2}$ \\ Published online: 8 December 2021 \\ C) Saudi Society for Geosciences 2021
}

Retraction Note: Arabian Journal of Geosciences (2021) 14: 1197 https://doi.org/10.1007/s12517-021-07412-9

The Editor-in-Chief and the Publisher have retracted this article because the content of this article is nonsensical. The peer review process was not carried out in accordance with the Publisher's peer review policy. Author Shuting Deng has not responded to correspondence regarding this retraction. The Publisher has not been able to obtain a current email address for author Yi Xia.

The original article can be found online at https://doi.org/10.1007/ s12517-021-07412-9.

Shuting Deng dengst4561@163.com

1 Fuzhou Technology and Business College, Fuzhou 350715, Fujian, China

2 East China Jiaotong University, Nanchang 330013, Jiangxi, China 